\title{
Model Systems in Heterogeneous Catalysis: Selectivity Studies at the Atomic Level
}

\author{
H. -J. Freund
}

Published online: 4 April 2008

(C) The Author(s) 2008

\begin{abstract}
Reaching 100\% selectivity is the theme of the twentyfirst century in heterogeneous and heterogenized homogeneous catalysis. To study chemical reactivity at the atomic scale, model systems have been prepared and characterized. We discuss selectivity of hydrogenation and dehydrogenation reactions on supported Pd particles, methanol oxidation at vanadium oxide model catalysts and, at last, the design of model catalysts with a well defined charge state of the metal, i.e., Au catalyst model systems.
\end{abstract}

Keywords Catalysis $\cdot$ Selectivity $\cdot$ Nanoparticles ·

Adsorption $\cdot$ Reaction

\section{Introduction}

Activity has always been an important characteristic for a heterogeneous or homogeneous catalyst [1]. Modifying a catalyst in such a way that it becomes $100 \%$ selective for a given chemical reaction is a task for the twentyfirst century. Understanding selectivity at the atomic scale is therefore important. In general, heterogeneous catalysts are complex materials and it is difficult to achieve this goal due to the presence of many different, possibly active sites. In this respect, a homogeneous catalyst represents a rather well-defined material exposing single sites, thus favoring high selectivity. There have been many attempts to heterogenize homogeneous catalysts by binding a homogeneous active complex to a solid surface in order to combine the advantages of homogeneous and heterogeneous catalysts

H.-J. Freund $(\bowtie)$

Fritz-Haber-Institut der Max-Planck-Gesellschaft,

Faradayweg 4-6, 14195 Berlin, Germany

e-mail: freund@fhi-berlin.mpg.de
[1]. In order to get insight into the atomic detail of such classes of catalysts strategies to circumvent the complexity of the "real" catalyst and to design models with a sufficient degree of complexity are a necessity.

These strategies have been developed during the last two decades and have been documented in several reviews [2-7].

Here, we will discuss a few recent examples from the author's laboratory, i.e., methanol dehydrogenation on Pd nanoparticles $[8,9]$, methanol oxidation on vanadia surfaces [10], ethene hydrogenation on Pd nanoparticles [11-14], and $\mathrm{CO}$ adsorption on $\mathrm{Au}$ atoms and clusters [15-18].

\section{Experimental Techniques}

The experiments were performed in a variety of ultrahigh vacuum systems built and situated at the Fritz Haber Institute of the Max Planck Society in Berlin. For details please consult the literature [5, 19].

\subsection{Model Catalysts}

Within a variety of recent papers and reviews the preparation of model catalysts has been described [2-7, 19]. Briefly, Fig. 1a shows Pd nanoparticles grown on an alumina thin film support. The individual particles can be imaged down to atomic detail (Fig. 1b), so that the schematic representation of a nanoparticles (Fig. 1c) with all its different sites of facets, edges, and corners has a realistic basis [20].

The first example discussed here involves the oxidative dehydrogenation of methanol to $\mathrm{CO} / \mathrm{CO}_{2}$ and $\mathrm{H}_{2} \mathrm{O}$. A detailed kinetic study using molecular beams [9] has demonstrated that the selectivity of the reaction 
Fig. 1 (a) A $650 \times 650 \AA^{2}$ image of Pd nanoparticles nucleated at steps and domain boundaries of a this alumina film grown on $\mathrm{NiAl}(000)$. (b) Atomic resolution images of crystalline Pd nanoparticles. $45 \times 45 \AA^{2}$ images. The resolution is kept a few layers down the sides, allowing identification of the side facets. The dots indicate atomic positions consistent with a (111) facet. $I_{t}=-1.8 n A, V_{s}=$ $-1.5 m V$ [20]. (c) Schematic representation of a crystalline truncated cubo-octaedron of Pd on and oxide surface. Different potential adsorption sides are indicated by shading [16]
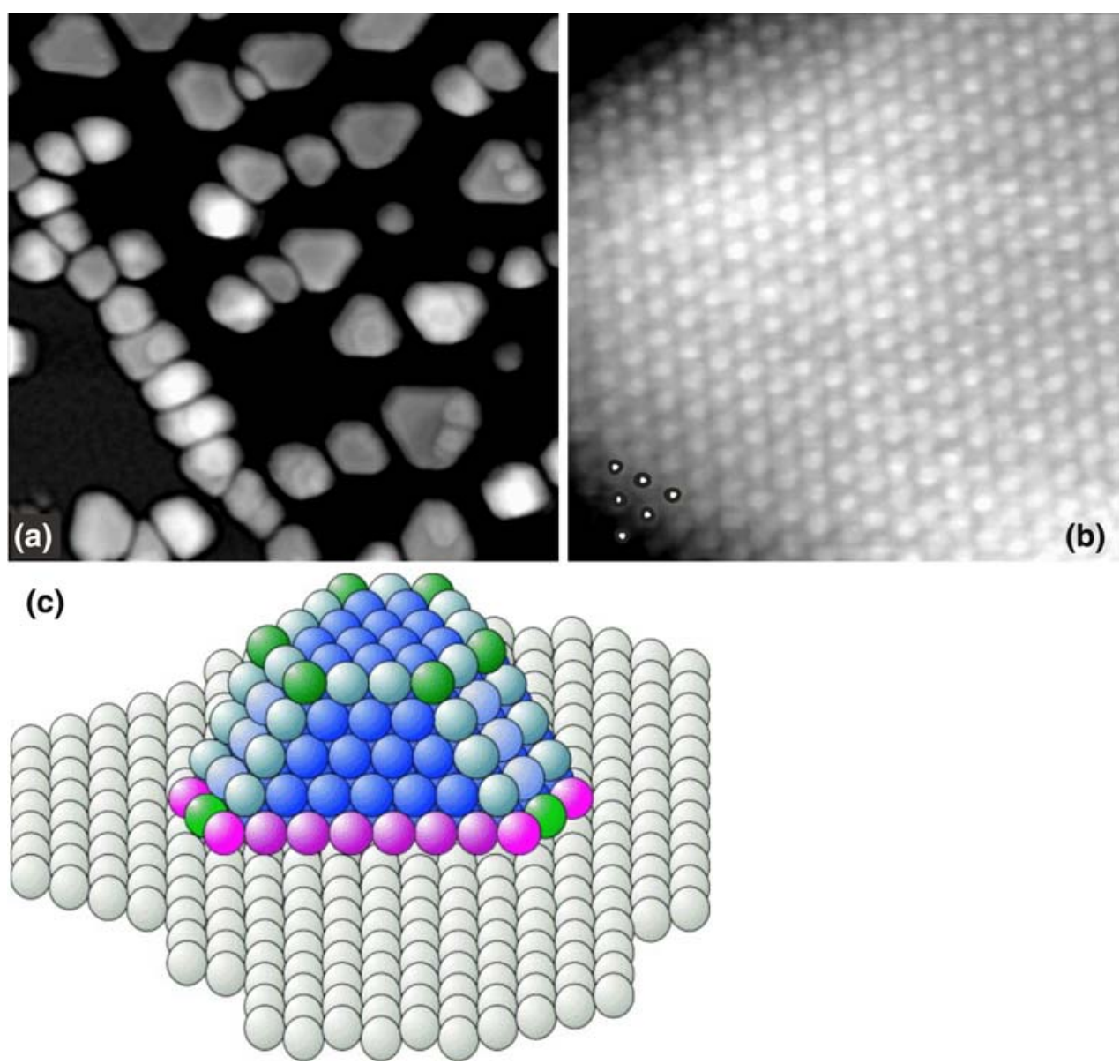

leading to the deposition of carbonaceous species at those sites [8, 9]. An increase in methanol pressure leads to deposition of carbonaceous species on the particle. The dehydrogenation reaction proceeds then mainly on the (111) facets of the nanoparticles, or, for that matter, similar to the situation on a $\operatorname{Pd}(111)$ single crystal surface $[21,22]$. Using ambient pressure polarization modulation infrared spectroscopy we are in a position to identify (Fig. 3) formyl and formaldehyde species on the surface and the products in the gas phase simultaneously [22]. Ambient pressure XPS measurements [23] indicate the formation of carbonaceous species at this stage. It is likely that formaldehyde and formyl species are precursors to $\mathrm{C}-\mathrm{O}$ bond cleavage, because, once all hydrogen has been removed and $\mathrm{CO}$ has been formed, $\mathrm{C}-\mathrm{O}$ bond cleavage is suppressed. Pd nanoparticles supported on the alumina film and $\mathrm{Pd}(111)$ single crystal surfaces do not dissociate $\mathrm{CO}$ even at elevated temperatures and gas pressures [24]. C-O bond cleavage is greatly attenuated if oxidative methanol dehydrogenation toward the selective formation of formaldehyde is studied on oxide surfaces and clusters as opposed to metal particles and surfaces, which brings us to the second example. To this end, we have studied $\mathrm{VO}_{x}$ particles supported on alumina and silica film supports [10]. As an example to judge the 
Fig. 3 (a) Surface $(\mathrm{p}-\mathrm{s})$ and (b) gas-phase $(\mathrm{p}+\mathrm{s})$ PM-IRAS spectra measured during $\mathrm{CH}_{3} \mathrm{OH}$ oxidation at $300-400 \mathrm{~K}$ [5 mbar $\mathrm{CH}_{3} \mathrm{OH}$ added at $300 \mathrm{~K}$ (trace 1) prior to 5 mbar $\mathrm{O}_{2}$ (trace 2)]. Spectra 3 and 4 were acquired during the oxidation reaction at $400 \mathrm{~K}$, after 15 and 60 min, respectively [22]
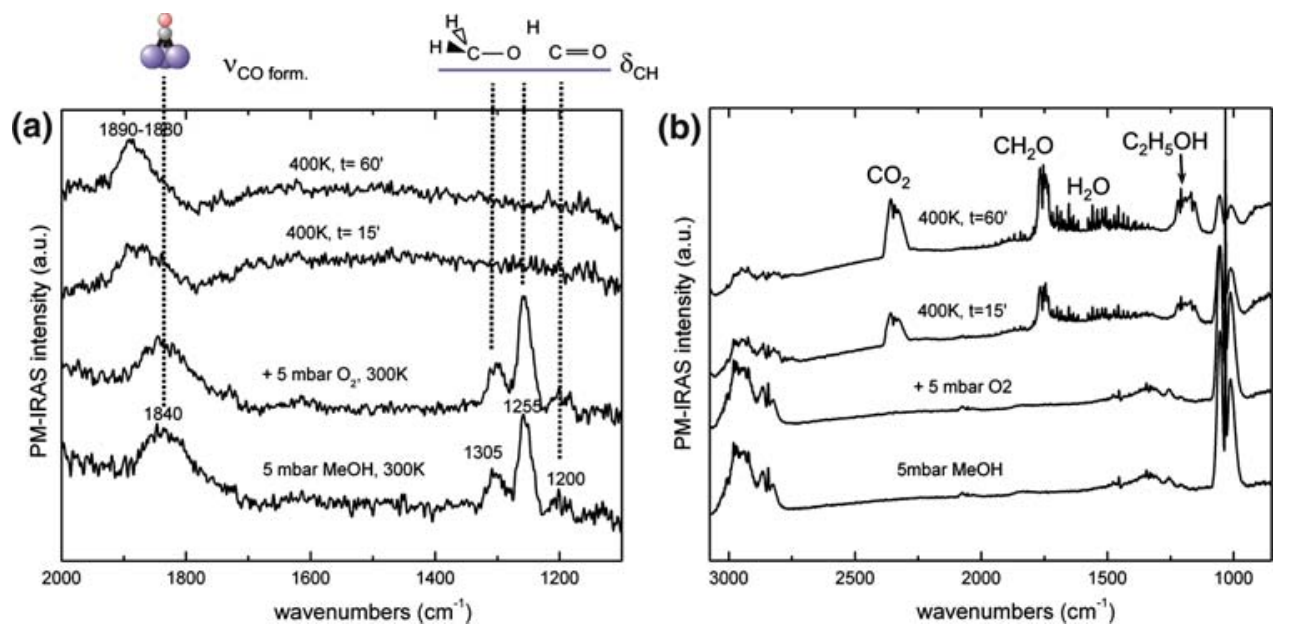

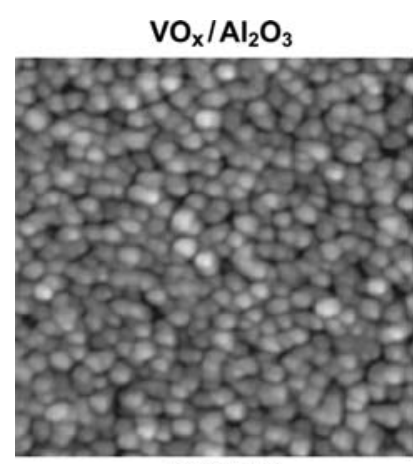

$0.32 \mathrm{MLV}$

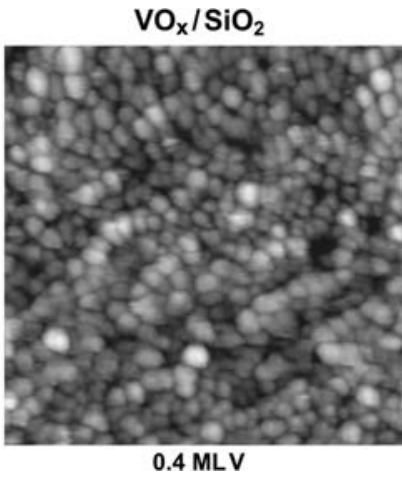

$0.4 \mathrm{MLV}$

Fig. 4 Comparison of two STM images $(50 \mathrm{~nm}$ x $50 \mathrm{~nm})$ measured for alumina- and silica-supported vanadia particles of similar $\mathrm{V}$-content. Tunneling was performed at the following conditions: $U=2.2 \mathrm{~V}, I=0.07 \mathrm{nA} \quad\left(\mathrm{VO}_{x} / \mathrm{Al}_{2} \mathrm{O}_{3}\right) ; \quad U=3.3 \mathrm{~V}, I=0.12 \mathrm{nA}$ $\left(\mathrm{VO}_{x} / \mathrm{SiO}_{2}\right)$. In both cases, particle number densities between $\sim 1.8$ $1.9 \times 10^{13}$ and $1.9 \times 10^{13}$ particles per $\mathrm{cm}^{-2}$ were determined [27]

morphology of the systems Fig. 4 shows $\mathrm{VO}_{x}$ aggregates on alumina and silica. We find a granular morphology as opposed to a wetting $\mathrm{VO}_{x}$ film. The $\mathrm{VO}_{x}$ particles contain vanadium in oxidation state $3+[25,26]$ as in $\mathrm{V}_{2} \mathrm{O}_{3}$, only at the surface the oxidation state is likely to be higher as indicated by the presence of vanadyl species which exhibit a characteristic feature around $1,050 \mathrm{~cm}^{-1}$ in the infrared spectrum [27]. Note that for $\mathrm{V}_{2} \mathrm{O}_{3}(0001)$ single crystalline surfaces such as vanadyl species have also been found and shown to be connected with an increase in oxidation state close to +5 as observed on $\mathrm{V}_{2} \mathrm{O}_{5}$ [27-29]. The selectivity toward methanol oxidation to formaldehyde depends on the degree of reduction of the vanadyl covering the surface: a fully vanadyl covered particle is inactive and a fully reduced surface is active; however, less active than an optimal arrangement of vanadyl and reduced sites at an intermediate reduction stage. It is this arrangement that controls the selectivity $[30,31]$. Again, on single crystalline $\mathrm{V}_{2} \mathrm{O}_{3}(0001)$ surfaces these phenomena have been studied in

detail, combining imaging techniques (STM) and spectroscopy as well as TDS. The results will be published elsewhere [32].

$\mathrm{VO}_{x}$ species on an oxide support still represent a typical heterogeneous catalyst. In order to proceed towards the principles of heterogenizing homogeneous catalysts it is necessary to bind individual atoms or compounds to a support and modify its ligand sphere [33-35]. We have started activities in this direction for alumina and silica supports which are summarized in a recent review article [35]. Briefly, $\mathrm{V}$ atoms, for example, may be evaporated onto alumina at low temperature which allows us to keep the atoms from agglomerating. Exposing the adsorbed atoms to $\mathrm{CO}$ we find a series of sharp bands (Fig. 5) which are assigned to $\mathrm{V}$ atoms with an increasing $\mathrm{CO}$ ligand sphere, i.e., from $\mathrm{VCO}$ to $\mathrm{V}(\mathrm{CO})_{2}$ to $\mathrm{V}(\mathrm{CO})_{3}$. If we stop the $\mathrm{CO}$ exposure at different stages it is possible to isolate the various species and identify the number of attached ligands by isotopic labeling experiments [33]. The isotopic labeling patterns observed and shown in Fig. 5 are characteristic for the three observed stoichiometries. This example should document the ability to control single sites and their coordination to molecules adsorbed from the gas phase.

The formation of carbonaceous species is seen to be a decisive factor in oxidative dehydrogenation of alcohols but also in hydrogenation of alkenes [11-14, 36-40]. In the latter case the carbon deposits control the relative amount of the alkene and hydrogen at the surface. However, here a second factor is important, namely the presence of hydrogen within the Pd nanoparticle, as schematically shown in Fig. 6 [12-14]. This subsurface hydrogen documents itself by a low temperature feature within the hydrogen thermal desorption spectrum and there was no direct proof for its presence within the particles until recently. In principle, there are techniques available that would allow us to investigate the depth profile of hydrogen, for example, using the so-called resonant-nuclear-reaction analysis 
Fig. 5 IR spectra taken from alumina supported vanadium atoms exposed to small but increasing doses of CO. (a) IR spectra of $\mathrm{CO}$ uptake at $90 \mathrm{~K} \mathrm{IR}$ spectra with ${ }^{12} \mathrm{CO},{ }^{13} \mathrm{CO}$ and equimolar natures. (b)

Adsorption of small amounts of $\mathrm{CO}$ to isolate the initial species. (c) Species after CO saturation and subsequent heating to 220 K. (d) Spectra after CO saturation and subsequent heating to $310 \mathrm{~K} \mathrm{[33]}$ (a)

$\mathrm{CO} / \mathrm{V} / \mathrm{Al}_{2} \mathrm{O}_{3}(90 \mathrm{~K})$

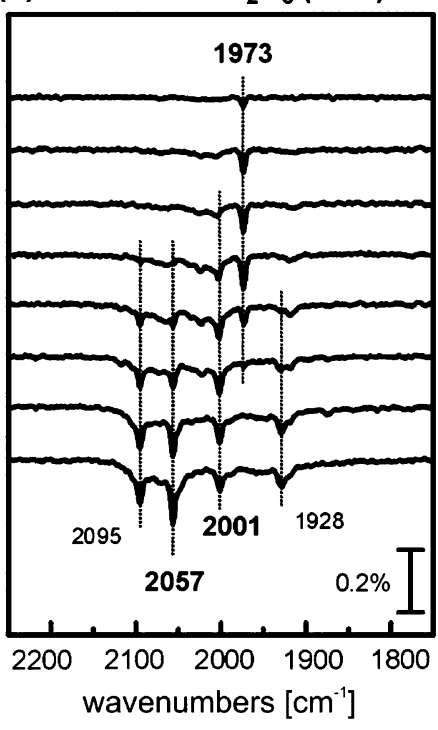

(c)

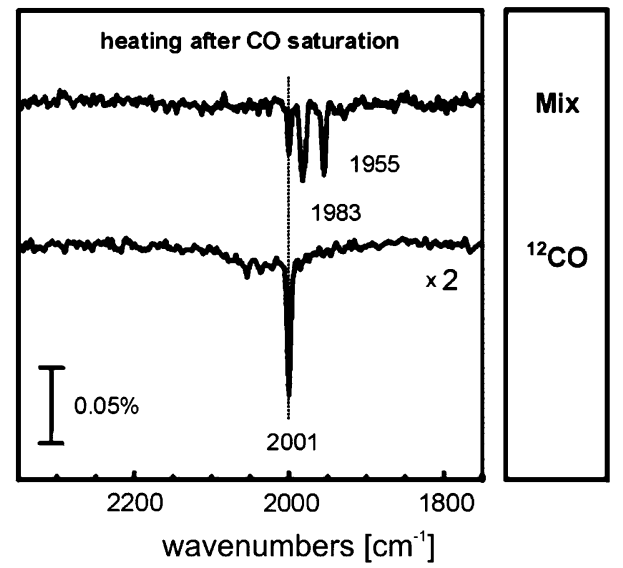

(b) vco

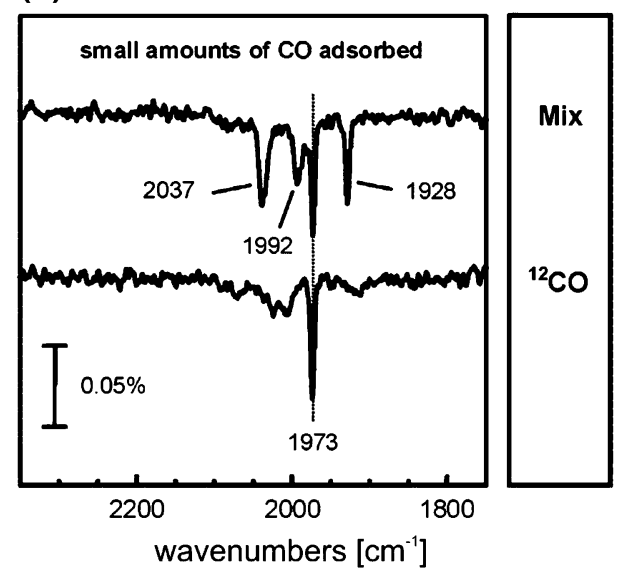

(d) $\quad \mathrm{V}(\mathrm{CO})_{3}$

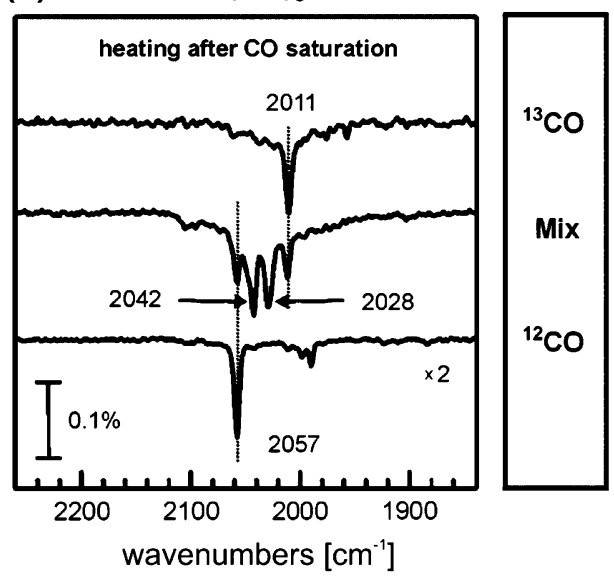

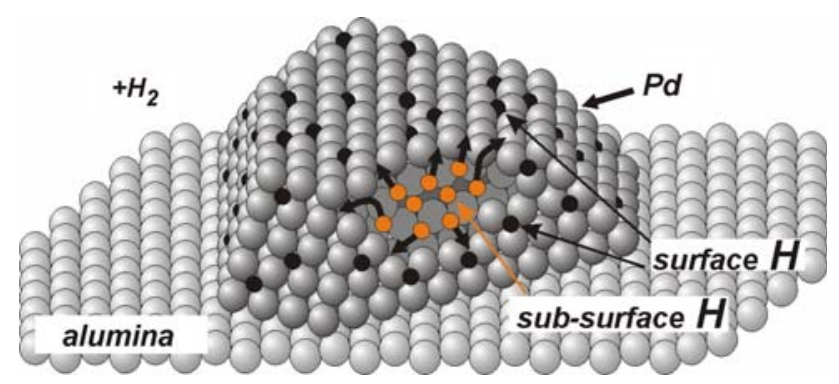

Fig. 6 Schematic representation of a Pd nanoparticle with hydrogen at surface and subsurface sites [12]

[41-43]. Experiments in this direction for the specific systems discussed above are under way. There is, indirect evidence that subsurface hydrogen participates in the reaction. For example, the hydrogenation of ethene to ethane strongly correlates with the presence of the low temperature TDS feature [12-14, 36, 37]. It is not clear in which way the subsurface hydrogen influences the reaction.
There is obviously exchange with surface hydrogen as it is not possible to populate surface and subsurface hydrogen separately [11-14]. Therefore, in the present case, it is not believed that subsurface hydrogen directly attacks the molecule, as was suggested by Ceyer for Ni [44-46], but rather modifies the properties of the entire near surface hydrogen population so as to enhance reactivity. If we modify the size of the Pd nanoparticles over a range from 1 to $6 \mathrm{~nm}$, ethene hydrogenation does not show strong variations both under ultrahigh vacuum conditions as well as under ambient conditions [11, 47], as expected from catalytic data. The reaction in thus called structure insensitive. The extrapolation to other alkenes has to be done with caution, as the interaction of the alkene with the surface varies with size. It appears that small molecules such as ethene react through the so-called $\pi$-bonded surface complex [36, 37, 47] while for others, such as pentene, the $\sigma$-bonded complex have been suggested to be the active surface intermediate which then also induces some structure 


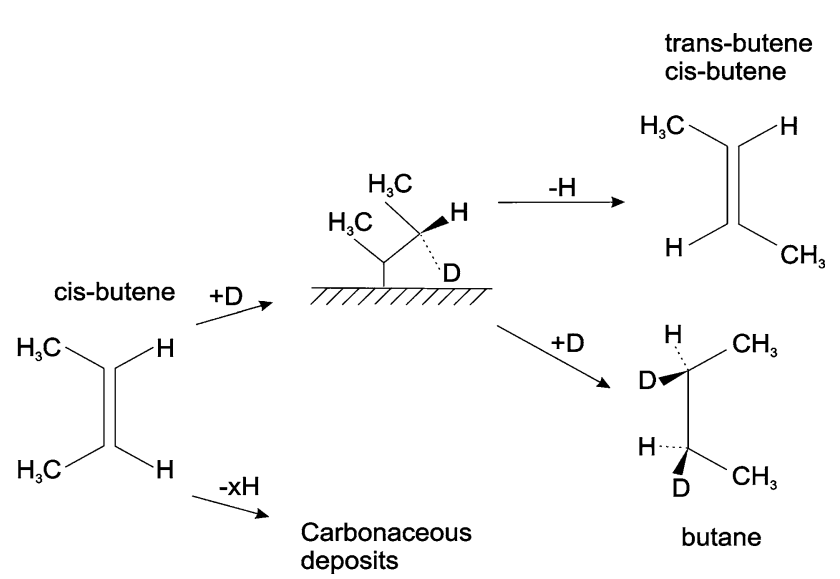

Fig. 7 Schematic diagram of the so-called Horiuti-Polanyi-mechanism for alkene hydrogenation. cis-butene undergoes stepwise hydrogenation or loss of hydrogen after the first hydrogenation step has happened (upper route). It may also dehydrogenate to carbonaceous deposits (lower route) [48]

sensitivity [14]. This is reasonable as the ordering around the surface intermediate has to be higher to support a $\sigma$-bonded precursor which requires two correlated sites.

It is generally accepted that hydrogenation involves the steps proposed via the so-called Polanyi-Horiuti-mechanism [48] that is schematically shown in Fig. 7. This mechanism leads to predictions on stereospecific aspects of the reaction involving cis-trans isomerization during the course of the various reaction branches, i.e., dehydrogenation, H-D exchange, and hydrogenation. Zaera and his group [49-54] have studied this reaction in detail on $\mathrm{Pt}(111)$ surfaces but there are no systematic studies available for nanoparticles. In collaboration with Zaera's group we have started to investigate hydrogenation of cis- and trans-2 butene on supported Pd nanoparticles using molecular beam techniques and TDS [55]. We observe interesting differences in comparison with reactions on single crystal surfaces, in particular with respect to sustained catalytic activity and selectivity, influence of carbonaceous deposits and stereochemistry which will be reported in a separate publication [55].

So far we have discussed particle size, the presence of particle-specific defects and surface modifiers as principles to control the reactivity and selectivity of a catalyzed reaction. There may be other parameters as well that would be important, to control. One such parameter is the charge on the supported metal. It has recently been proposed that the charge may be controlled by depositing metals on oxide thin films of well-defined thickness which are themselves deposited on a metallic support [16]. The concepts are similar to those used in semiconductor industry. Learning to modify band offsets at underlying interfaces by controlling interfacial dipoles may hold great promise in catalysis as well.
In the following I will briefly discuss the concepts and the presently available knowledge.

It has been recognized that the thickness of oxide films, as they are grown on metal substrates, may be used as a design parameter to create materials of potential in catalysis. A concept to control the catalytic activity of a dispersed metal by the thickness of an insulating oxide layer was introduced some 20 years ago by Maier and coworkers using silica layers covering Pt [56-59]. In this case the catalytic performance for dehydrogenation of cycloalkenes depends significantly on the thickness of the silica films, which was explained by the decreasing transport of hydrogen atoms produced at the Pt surface through the silica film. The main experimental challenge, however, is to provide undisputable proof for the proposed mechanisms which is usually hampered either by the complexity of the samples investigated and/or the lack of appropriate methodology to exclude interference with alternative mechanisms. Developing experimental control together with realistic theoretical modeling, with respect to the thickness and structure of the oxide films [7], allows these structural properties to be used to control their functional characteristics and, thus, the catalytic properties of a metal deposited onto them. Here, control may concern transport of species, e.g., hydrogen or oxygen, through the film or it may concern electronic interaction of the interior metaloxide interface with adsorbed species on top.

On the basis of density functional theory (DFT) calculations it was recently proposed by Pacchioni and his coworkers that charge transfer may also occur for metal atoms (as opposed to oxygen in the case of the CabreraMott mechanism) and metal clusters adsorbed on a supported thin oxide film, provided that the adsorbed metal exhibits a high electronegativity and the oxide film does not exceed a few mono-layers [15, 18]. In particular, Au atoms adsorbed on thin $\mathrm{MgO}(001)$ films grown on $\mathrm{Mo}(001)$ and $\operatorname{Ag}(001)$ are expected to be negatively charged in contrast to their counterparts on the corresponding bulk $\mathrm{MgO}$ (or thick $\mathrm{MgO}$ films) [15, 18]. In the latter case it was proven that Au atoms are essentially neutral [60]. Thus, the thickness of the oxide film may serve as a parameter to tune the electronic properties of supported metals. Pacchioni and co-workers discussed the phenomenon in terms of the modification of the work function in the thin film system and the electronegativity (electron affinity) of the adsorbed species [61]. It is also connected to the ability of thin films to structurally relax upon charge transfer, i.e., the phenomenon contains a polaronic component stabilizing the charge transfer [18].

Recently, it was demonstrated through modeling how different oxides may lead to drastic changes of the potential step [61]. The reasons for the predicted changes are very different, depending on the type of oxide. 
Apparently, ionic oxides such as $\mathrm{MgO}$ cause a decrease of the surface potential step of metals such as Ag or Mo because the $\mathrm{O}^{2-}$ ions polarize the metal electrons away from the interface, effectively modifying the electron density and thus depleting the metal surface of electrons [62]. This effect strongly depends on the distance between the ionic layer and the top metal layer. In the case of more covalent oxides this effect is less strong. Here, the oxygen ions still have some electron accepting ability leading to an accumulation of charge in the local metal substrate-oxygen bonds. This, in turn leads to an increase in the surface potential step. $\mathrm{SiO}_{2}$ appears to be a good example for the latter case. In addition, there is an interesting trend observed in the theoretical predictions on the change of level alignment as the number of oxide layers increases: except for the case of a single oxide layer, which establishes a special situation, there is little change in the level alignment as the film gets thicker than two layers [61]. However, as the film thickens it loses its ability to structurally relax.

With all this information in mind, it is foreseen, that by controlling the thickness of an oxide layer one has a unique opportunity to control charge transfer from the oxide-modified metal support to an adsorbate without using electrical control but by pure chemical means. If one could ensure stability under reaction conditions, thin oxide films on metallic supports would present a possibility to design model catalyst supports which control the charge state of an adsorbed species depending on their electronegativity. Of course, based on what has been discussed above, the oxide film cannot be thicker than the tunneling length. When growing oxide layers with thicknesses well exceeding this length, the relation of work function and electronegativity would still be favoring charge transfer to or from the adsorbed species but the electronic interaction would be shut off.

There is increasing evidence that the above scenario may hold true, and that it may indeed be realized [63]. In an effort to confirm the predictions of Pacchioni and his co-workers from 2005 [15], Pd and Au adsorption has been studied on thick and thin $\mathrm{MgO}(100)$ layers while the morphology of the film was controlled via scanning tunneling microscopy and other means [63]. While Pd remains in the neutral state on both, thin and thicker substrates, $\mathrm{Au}$ has been shown to be neutral on the thicker film [60], while it charges negatively on a three layer thick film [63]. The charge state of $\mathrm{Au}$ on the thick film was measured in electron spin resonance experiments [60]. When $\mathrm{Au}$ is negatively charged on the thin $\mathrm{MgO}$ film, the distribution of atoms changes dramatically as revealed in Fig. 8 [63]. The Au atoms (Fig. 8a), due to their negative charge repel each other and built up a monolayer of low Au coverage with an average inter-atom distance of more than $1.5 \mathrm{~nm}$. Figure $8 b$ shows the distribution of $\mathrm{Pd}$ on a $\mathrm{MgO}(100)$ film of the same thickness. Most of the imaged protrusions are due to Pd atoms, very few larger aggregates containing a few atoms are also visible as slightly larger and brighter protrusions. The distribution of the Pd atoms is, in contrast to the $\mathrm{Au}$ atoms, typical for a statistical distribution of $\mathrm{Pd}$ atom distances [63] in a situation where the temperature is sufficiently low for long range diffusion not to occur.

$\mathrm{Had} \mathrm{Au}$ been deposited on a metallic surface, such as $\mathrm{Ag}(001)$, the distribution of Au atoms would have been very similar to that observed for Pd on all $\mathrm{MgO}$ substrates (not shown, see [63]). If Au is deposited on a thin alumina film, on the other hand, Au forms chains, whose length and orientation is determined by the interaction with the underlying $\mathrm{NiAl}(110)$ metallic alloy support (Fig. 9) [64, 65].

This exemplifies another important control parameter: the buried metal/oxide interface may be used to control the shape of the adsorbed species! Recently, Ricci et al. [66] predicted that $\mathrm{Au}$ nanoparticles change shape when they are deposited on a thin $\mathrm{MgO}$ film supported on a metal instead of a bulk $\mathrm{MgO}$ surface. Apparently, this change is induced by electrostatic interaction between the underlying metal and the metal-induced excess charge at the cluster
Fig. 8 STM images $(30 \mathrm{~nm} \times 30 \mathrm{~nm})$ of $(\mathbf{a}) \mathrm{Au}$ atoms adsorbed on $3 \mathrm{ML}$ thin $\mathrm{MgO}$ films $(\theta=2.9 \% \mathrm{ML} \mathrm{Au}$, $\left.V_{\mathrm{S}}=+0.5 \mathrm{~V}, \mathrm{I}_{\mathrm{T}}=11 \mathrm{pA}\right) ;(\mathbf{b})$ $\mathrm{Pd}$ atoms adsorbed on $3 \mathrm{ML}$ thin $\mathrm{MgO}$ films $(\theta=2.3 \% \mathrm{ML}$ $\left.\mathrm{Pd}, V_{\mathrm{S}}=+0.2 \mathrm{~V}, \mathrm{I}_{\mathrm{T}}=13 \mathrm{pA}\right)$ [63]. The images were taken at low temperature $(4 \mathrm{~K})$. A flat $\mathrm{MgO}$ terrace is imaged with $\mathrm{Au}$ and Pd atoms (bright protrusions) distributed across the surface. $\mathrm{MgO}$ islands of thicker $\mathrm{MgO}$ films are imaged as brighter areas [63]
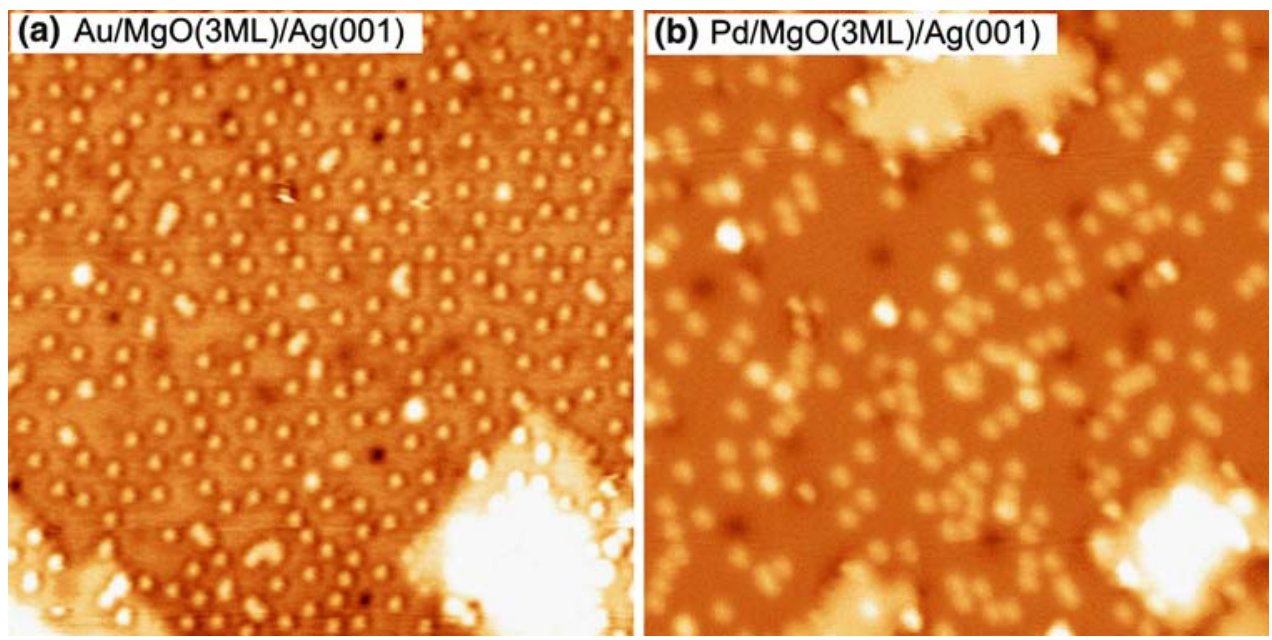


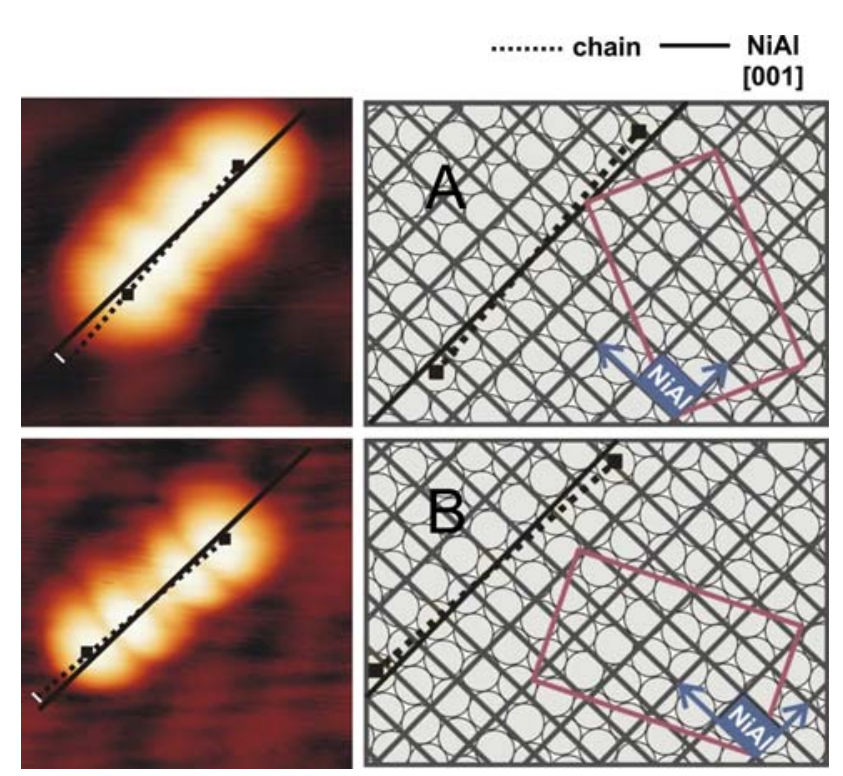

Fig. 9 Au chains on alumina. The alumina films grow in two domains $(\mathrm{A}+\mathrm{B})$ on the $\mathrm{NiAl}(110)$ substrate. The orientation of the Au chains is determined by its interaction with the substrate, as indicated in the schematic representation in the panels on the right [64]

oxide interface. This is accompanied with a crossover from 3-D geometries to 2-D structures. These 2-D Au cluster structures have also been experimentally observed in the gas phase [67]. There is now experimental evidence that corroborates this prediction for $\mathrm{MgO}$ thin films [68].

In order to open up opportunities in applications, ultrathin oxide film systems need to be prepared on granular (powder) substrates. There are thin film oxide systems exhibiting self limiting growth. For example, alumina films grown on a NiAl alloy surface show such behavior [69]. In this respect, metal alloy systems, in general, could offer possibilities.

\section{Conclusions}

The examples discussed indicate that model studied may provide useful information on catalytic reactions, even under realistic, i.e., technically relevant conditions, provided the systems studied contain the appropriate degree of complexity. In particular structure/morphology—spectroscopy and-reactivity relations, which are difficult to reach at the atomic level with real powder samples, allow us to achieve a new level of insight into heterogeneous reactions. A number of parameters influencing selectivity may be varied independently for model systems allowing clarification of heuristic concepts in heterogeneous catalysis.

Acknowledgments The author is grateful to his collaborators whose names appear in the references as well as to a number of agencies including the Deutsche Forschungsgemeinschaft and the Fonds der
Chemischen Industrie. Particular thanks go to Gianfranco Pacchioni and Joachim Sauer for stimulating discussions on theory.

Open Access This article is distributed under the terms of the Creative Commons Attribution Noncommercial License which permits any noncommercial use, distribution, and reproduction in any medium, provided the original author(s) and source are credited.

\section{References}

1. Ertl G, Knözinger H, Weitkamp J (eds) (1997) Handbook of heterogeneous catalysis, chapter 1 . Wiley-VCH Verlagsgesellschaft $\mathrm{mbH}$, Weinheim

2. Campbell CT (1997) Surf Sci Rep 27:1

3. Henry CR (1998) Surf Sci Rep 31:231

4. Freund H-J (1997) Angew Chem Int Ed 36:452

5. Freund H-J, Bäumer M, Libuda J, Risse T, Rupprechter G, Shaikhutdinov S (2003) J Catal 216:223

6. Goodman DW (2003) J Catal 216:213

7. Freund H, Goodman DW (2007) In: Ertl G, Knözinger H, Schüth F, Weitkamp J (eds) Handbook of heterogeneous catalysis, 2nd edn. Wiley-VCH Verlagsgesellschaft mbH, Weinheim

8. Freund H-J, Libuda J, Bäumer M, Risse T, Carlsson AF (2003) Chem Rec 3:181

9. Schauermann S, Hoffmann J, Johanek V, Hartmann J, Libuda J, Freund H-J (2002) Angew Chem Int Ed 41:2532

10. Magg N, Immaraporn B, Giorgi J, Schroeder T, Bäumer M, Döbler J, Wu Z, Kondratenko E, Cherian M, Baerns M, Stair PC, Sauer J, Freund H-J (2004) J Catal 226:88

11. Freund H-J (2005) Catal Today 100:3

12. Doyle AM, Shaikhutdinov S, Jackson SD, Freund H-J (2003) Angew Chem Int Ed 42:5240

13. Doyle AM, Shaikhutdinov S, Freund H-J (2004) J Catal 223:444

14. Doyle AM, Shaikhutdinov S, Freund HJ (2005) Angew Chem Int Ed 44:629

15. Pacchioni G, Giordano L, Baistrocchi M (2005) Phys Rev Lett 94:226104

16. Freund H-J (2007) Surf Sci 601:1438

17. Sterrer M, Yulikov M, Fischbach E, Heyde M, Rust HP, Pacchioni G, Risse T, Freund H-J (2006) Angew Chem Int Ed 45:2630

18. Giordano L, Pacchioni G (2006) Phys Chem Chem Phys 8:3335

19. Bäumer M, Freund H-J (1999) Prog Surf Sci 61:127

20. Hansen KH, Worren T, Stempel S, Lægsgaard E, Bäumer M, Freund HJ, Besenbacher F, Stensgaard I (1999) Phys Rev Lett 83:4120

21. Morkel M, Rupprechter G, Freund H-J (2005) Surf Sci 588:L209

22. Borasio M, Rodrigez de la Fuente O, Rupprechter G, Freund HJ (2005) J Phys Chem B 109:17791

23. Kaichev VV, Morkel M, Unterhalt H, Prosvirin IP, Bukhtiyarov VI, Rupprechter G, Freund HJ (2004) Surf Sci 566-568:1024

24. Rupprechter G, Kaichev VV, Unterhalt H, Morkel M, Bukhtiyarov VI (2004) Appl Surf Sci 235:26

25. Magg N, Giorgi JB, Schroeder T, Baumer M, Freund HJ (2002) J Phys Chem B 106:8756

26. Magg N, Giorgi JB, Hammoudeh A, Schroeder T, Baumer M, Freund HJ (2003) J Phys Chem B 107:9003

27. Abu Haija M, Guimond S, Romanyshyn Y, Uhl A, Kuhlenbeck H, Todorova TK, Ganduglia-Pirovano MV, Dobler J, Sauer J, Freund HJ (2006) Surf Sci 600:1497

28. Dupuis AC, Abu Haija M, Richter B, Kuhlenbeck H, Freund HJ (2003) Surf Sci 539:99

29. Guimond S, Abu Haija M, Kaya S, Lu J, Weissenrieder J, Shaikhutdinov S, Kuhlenbeck H, Freund H-J, Döbler J, Sauer J (2006) Top Catal 38:117 
30. Kaya S, Sun YN, Weissenrieder J, Stacchiola D, Shaikhutdinov S, Freund HJ (2007) J Phys Chem C 111:5337

31. Kaya S (2007) Thesis, Humboldt -Universität zu Berlin, Berlin

32. Romanyshyn Y, Guimond S, Göbke D, Sturm M, Kuhlenbeck H, Freund H-J, Ganduglia-Pirovano MV, Döbler J, Sauer J, Top Catal (submitted)

33. Magg N, Giorgi J, Frank M, Immaraporn B, Schroeder T, Bäumer M, Freund H-J (2004) J Am Chem Soc 126:3613

34. Immaraporn B, Magg N, Kaya S, Wang J, Baumer M, Freund HJ (2004) Chem Phys Lett 392:127

35. Risse T, Freund H-J (2005) In: Copéret C, Chaudret B (eds) Topics organometallic chemistry, vol 16. Springer Verlag, p 117

36. Shaikhutdinov S, Heemeier M, Bäumer M, Lear T, Lennon D, Oldman RJ, Jackson SD, Freund H-J (2001) J Catal 200:330

37. Shaikhutdinov S, Frank M, Bäumer M, Jackson SD, Oldman RJ, Hemminger JC, Freund H-J (2002) Catal Lett 80:125

38. Teschner D, Pestryakov A, Kleimenov E, Havecker M, Bluhm H, Sauer H, Knop-Gericke A, Schlogl R (2005) J Catal 230:195

39. Gabasch H, Kleimenov E, Teschner D, Zafeiratos S, Havecker M, Knop-Gericke A, Schlogl R, Zemlyanov D, Aszalos-Kiss B, Hayek K, Klotzer B (2006) J Catal 242:340

40. Teschner D, Vass E, Havecker M, Zafeiratos S, Schnorch P, Sauer H, Knop-Gericke A, Schlogl R, Chamam M, Wootsch A, Canning AS, Gamman JJ, Jackson SD, McGregor J, Gladden LF (2006) J Catal 242:26

41. Fukutani K (2001) Solid State Phys 36:353

42. Wilde M, Matsumoto M, Fukutani K, Liu ZM, Ando K, Kawashima Y, Fujieda S (2002) J Appl Phys 92:4320

43. Wilde M, Naschitzki M, Fukutani K, Freund H-J (in press) Phys Rev B

44. Maynard KJ, Johnson AD, Daley SP, Ceyer ST (1991) Farad Discuss Chem Soc 91:437

45. Haug KL, Burgi T, Trautman TR, Ceyer ST (1998) J Am Chem Soc $120: 8885$

46. Bürgi T, Trautman TR, Gostein M, Lahr DL, Haug KL, Ceyer ST (2002) Surf Sci 501:49

47. Somorjai GA, Rupprechter G (1999) J Phys Chem B 103:1623

48. Horiuti J, Polanyi M (1934) Trans Faraday Soc 30:1164

49. Davis SM, Zaera F, Somorjai GA (1982) J Catal 77:439
50. Zaera F, Somorjai GA (1984) J Am Chem Soc 106:2288

51. Davis SM, Zaera F, Gordon BE, Somorjai GA (1985) J Catal 92: 240

52. Godbey D, Zaera F, Yeates R, Somorjai GA (1986) Surf Sci 167:150

53. Janssens TVW, Stone D, Hemminger JC, Zaera F (1998) J Catal $177: 284$

54. Zaera F (2002) Appl Catal A 229:75

55. Brandt B, Ludwig W, Fischer K, Schauermann S, Zaera F, Freund H-J J Phys Chem C (submitted)

56. McEwen AB, Maier WF, Fleming RH, Baumann SM (1987) Nature 329:531

57. McEwen AB, Maier WF, Smith DA (1987) In: Ward JW (ed) Catalysis. Elsevier Science Publishers B.V., Amsterdam, p 823

58. Fleming RH, Baumann SM, Meeker GP, Maier WF (1987) In: Benninghoven A (ed) Secondary ion mass spectrometry: SIMS VI. John Wiley and Son Ltd, Paris

59. Cogen JM, Ezaz-Nikpay K, Fleming RH, Baumann SM, Maier WF (1987) Angew Chem Int Ed 26:1182

60. Yulikov M, Sterrer M, Heyde M, Rust HP, Risse T, Freund H-J, Pacchioni G, Scagnelli A (2006) Phys Rev Lett 96:146804

61. Giordano L, Cinquini F, Pacchioni G (2006) Phys Rev B 73:045414

62. Goniakowski J, Noguera C (2004) Interface Sci 12:93

63. Sterrer M, Risse T, Pozzoni UM, Giordano L, Heyde M, Rust HP, Pacchioni G, Freund H-J (2007) Phys Rev Lett 98:096107

64. Kulawik M, Nilius N, Freund HJ (2006) Phys Rev Lett 96:036103

65. Nilius N, Ganduglia-Pirovano MV, Brazdova V, Kulawik M, Sauer J, Freund H-J Phys Rev Lett (submitted)

66. Ricci D, Bongiorno A, Pacchioni G, Landman U (2006) Phys Rev Lett 97:036106

67. Furche F, Ahlrichs R, Weis P, Jacob C, Gilb S, Bierweiler T, Kappes MM (2002) J Chem Phys 117:6982

68. Sterrer M, Risse T, Heyde M, Rust H-P, Freund H-J (2007) Phys Rev Lett 98:206103

69. Jaeger RM, Kuhlenbeck H, Freund H-J, Wuttig M, Hoffmann W, Franchy R, Ibach H (1991) Surf Sci 259:235 